\title{
Influencia de la creatividad, competencias y colaboración del capital humano en el desempeño contextual de las instituciones de educación superior
}

\begin{abstract}
Incidence of Creativity, Competences and Collaboration of Human Capital in the Contextual Performance of Higher Education Institutions
\end{abstract}

\section{Influência da criatividade, habilidades e colaboração do capital humano no desempenho contextual das instituições de ensino superior}

\author{
Idolina Bernal González \\ Universidad Autónoma de Tamaulipas, México \\ ibernal@docentes.uat.edu.mx \\ https://orcid.org/0000-0001-6292-6173
}

\section{Resumen}

La presente investigación tiene como objetivo determinar la influencia que el capital humano, medido a través de los factores de creatividad, competencias y colaboración, tiene sobre el desempeño contextual de instituciones de educación superior localizadas en el estado de Tamaulipas, México, con la finalidad de brindar a la gerencia educativa información que sea de utilidad para potenciar el funcionamiento de su organización. El estudio se realizó bajo un enfoque cuantitativo, de alcance descriptivo-correlacional-explicativo con la participación de 95 encuestados. La técnica de análisis de datos implementada corresponde al modelo de regresión lineal. Así, como parte de los resultados, se logró determinar que la colaboración, competencias y creatividad del capital humano influyen positiva y significativamente en el desempeño contextual de instituciones de educación superior. Específicamente, se observó que la colaboración explica $36.1 \%$ el desempeño contextual del personal adscrito a estos centros educativos; las competencias tienen un aporte de $35 \%$ sobre esta variable, y la 


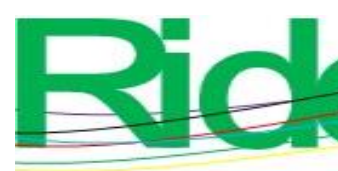

Revista Iberoamericana para la
Investigación y el Desarrollo Educativo
ISSN $2007-7467$

creatividad logró alcanzar $31 \%$ de incidencia en el desempeño contextual. Es decir: al existir mayores lazos de compañerismo y confianza entre los empleados, mayor será el desempeño alcanzado a nivel contextual. Asimismo, al poseer el personal las cualidades, competencias y aptitudes necesarias para el desarrollo de sus actividades, así como la creatividad y agilidad para solucionar problemas y generar nuevo conocimiento, el desempeño contextual será mayor positiva y significativamente, tal como lo evidencian los datos observados en la presente investigación.

Palabras clave: calidad educativa, capital humano, desempeño contextual, desempeño organizacional, eficacia educacional.

\section{Abstract}

The present research aims to determine the influence that human capital, measured through the factors of creativity, competences and collaboration, has on the contextual performance of higher education institutions located in the state of Tamaulipas, Mexico in order to provide educational management with information that is useful to enhance the operation of your organization. The study is carried out under a quantitative approach, descriptivecorrelational-explanatory scope with the participation of 95 respondents. The data analysis technique implemented corresponds to the linear regression model. As part of the results, it was observed that collaboration explains in $36.1 \%$ the contextual performance of the personnel assigned to these educational centers, while the competences have a contribution of $35 \%$ on this variable, and creativity managed to reach a $31 \%$ incidence in contextual performance. That is: as there are greater bonds of companionship and trust among employees, the higher the performance achieved at the contextual level. Likewise, as staff possess the qualities, competencies and aptitudes necessary for the development of their activities, as well as the creativity and agility to solve problems and generate new knowledge, the contextual performance will be positively and significantly higher, as evidenced by the data. observed in the present investigation.

Keywords: educational quality, human capital, contextual performance, organizational performance, educational effectiveness. 


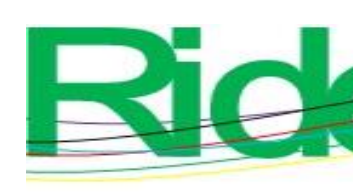

Revista Iberoamericana para la
Investigación y el Desarrollo Educativo
ISSN $2007-7467$

\section{Resumo}

O objetivo desta pesquisa é determinar a influência que o capital humano, medido através dos fatores de criatividade, competências e colaboração, tem no desempenho contextual de instituições de ensino superior localizadas no estado de Tamaulipas, México, a fim de fornecer gestão educacional com informações úteis para aprimorar a operação de sua organização. $\mathrm{O}$ estudo foi realizado sob abordagem quantitativa, com escopo descritivocorrelacional-explicativo e contou com a participação de 95 respondentes. A técnica de análise de dados implementada corresponde ao modelo de regressão linear. Assim, como parte dos resultados, foi determinado que a colaboração, as habilidades e a criatividade do capital humano influenciam positiva e significativamente o desempenho contextual das instituições de ensino superior. Especificamente, observou-se que a colaboração explica $36,1 \%$ do desempenho contextual do pessoal lotado nesses centros de ensino; as competências têm uma contribuição de $35 \%$ nesta variável e a criatividade consegue atingir um impacto de $31 \%$ no desempenho contextual. Ou seja, quanto mais laços de companheirismo e confiança existem entre os colaboradores, maior é o desempenho alcançado ao nível contextual. Da mesma forma, como os funcionários possuem as qualidades, competências e aptidões necessárias ao desenvolvimento de suas atividades, bem como a criatividade e agilidade para resolver problemas e gerar novos conhecimentos, o desempenho contextual será positiva e significativamente superior, conforme evidenciado pelo observado dados na presente investigação.

Palavras-chave: qualidade educacional, capital humano, desempenho contextual, desempenho organizacional, eficácia educacional.

Fecha Recepción: Octubre 2020

Fecha Aceptación: Julio 2021

\section{Introducción}

Las demandas sociales y exigencias del mercado laboral han propiciado en las últimas décadas que las organizaciones innoven en la implementación de mecanismos de mejora para la eficaz gestión de sus recursos y capacidades. Esto con la finalidad de hacer frente a los desafíos del entorno y ser cada vez más competitivas frente a las necesidades de la sociedad. Las organizaciones educativas no son la excepción en este quehacer institucional, sino que, por el contrario, en la actual era del conocimiento la educación juega un papel trascendental 


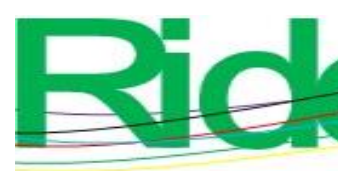

Revista Iberoamericana para la Investigación y el Desarrollo Educativo ISSN $2007-7467$

en el desarrollo social y en la economía nacional. En las instituciones de educación superior (IES) este rol es particularmente perceptible, puesto que en ellas recae la responsabilidad de formar a los profesionistas que en el futuro próximo se incorporarán al mercado laboral para acrecentar el valor de sus centros de trabajo.

Bajo esta perspectiva, es importante comentar que en los últimos años México ha presentado avances significativos en materia educativa. Sin embargo, tal como lo señala la Organización para la Cooperación y el Desarrollo Económicos [OCDE] (2019), aún quedan retos importantes por atender en la educación superior. De hecho, uno de ellos es la calidad que se oferta a los educandos, puesto que las estadísticas obtenidas por la OCDE ubican a México con índices inferiores a los promedios obtenidos por el resto de los países que integran esta organización, hallazgo que hace visible la necesidad de transformar la política pública hacia la modernización del sistema de educación superior, y así alinear sus objetivos a las cambiantes necesidades de la economía global.

La intención principal es que a través de la política educacional se diseñen líneas de acción que garanticen la pertinencia de los planes y programas de estudio, de tal manera que en su planeación se integren estrategias didácticas que coadyuven a elevar sustancialmente la calidad del aprendizaje de los alumnos, así como el desarrollo de competencias, habilidades y destrezas necesarias para su buen desempeño en el mercado laboral. En este sentido, las competencias y habilidades del capital humano que conforman la ciudadanía organizacional de las IES representan hoy por hoy uno de los eslabones de mayor valor en el logro de los objetivos establecidos por estos centros educativos. Puesto que, a través de las acciones y comportamientos del personal, se hace posible el cumplimiento de las estrategias organizacionales y la consecución de las políticas educativas emitidas por el sector. Lo anterior debido a que, más allá de la tecnología y las metodologías de trabajo, son las capacidades, conocimientos y saberes de docentes y administrativos los que permiten generar ventaja competitiva a la organización educacional (Di Doménico y De Bona, 2005; Segredo, 2016).

Bajo este contexto, resulta trascendente asegurar que el capital humano adscrito a las instituciones educativas de nivel superior cuente con las cualidades necesarias para el eficiente ejercicio de su función, ya que de ello dependerá el desempeño que estos centros de trabajo proyecten ante la sociedad y la nación (Durán, 2016; Samá, 2020; Vallejo y 


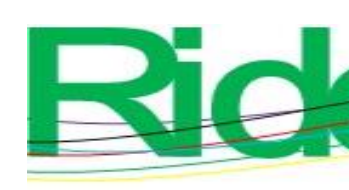

Revista Iberoamericana para la Investigación y el Desarrollo Educativo ISSN $2007-7467$

Portalanza, 2017). Ante ello, surge el interés de la presente investigación, que tiene como objetivo analizar la influencia que las competencias, creatividad y colaboración del capital humano tienen sobre el desempeño de las IES, principalmente en la faceta de desempeño contextual, la cual engloba conductas de apoyo social y psicológico que el personal de la institución manifiesta hacia sus compañeros de trabajo y la organización a fin de lograr las metas establecidas por la alta dirección (Borman, 2004; Borman y Motowidlo, 1993; Delgado et al., 2018).

La finalidad de este estudio es brindar a la alta dirección información oportuna y de utilidad para la generación de líneas de acción que fortalezcan los atributos intelectuales del capital humano en beneficio de un mejor desempeño y, por ende, una mejor educación para el alumnado.

\section{Marco teórico}

\section{Capital humano: concepto y factores principales}

El capital humano es uno de los términos que mayor valor ha cobrado en los discursos organizacionales por el impacto que este produce en la productividad laboral y crecimiento económico (Diene, Diene y Azomahou, 2016; Pelinescu, 2015; Ramírez, 2015; Valdés, Ocegueda y Romero, 2018). Autores como Hamadamin y Atan (2019) y McGuirk, Lenihan y Hart (2015) aseguran que si una empresa tiene una ventaja sobre otra lo más probable es que se deba a las capacidades del talento humano que la conforman, en términos de habilidades, experiencia y destrezas para trabajar.

A partir de la revisión de literatura, se ha descubierto lo polifacético que es este concepto de capital humano, por lo que aquí se ha optado por incluir no solo una sino varias de sus definiciones. Por ejemplo, Bontis, Chong y Richardson (2000) señalan que el capital humano es conceptualizado como el stock de conocimientos, competencias, actitudes y habilidad intelectual de los empleados para pensar en soluciones innovadoras ante los problemas suscitados en el área laboral. Asiaei y Josoh (2015) y Ifeanyichukwu (2017) comentan que el capital humano hace referencia al conjunto de habilidades, conocimientos y experiencias del personal que representan la base para el desarrollo organizacional. 


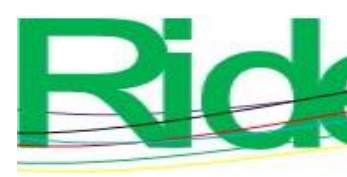

Revista Iberoamericana para la Investigación y el Desarrollo Educativo ISSN $2007-7467$

Otra definición relevante es la sugerida por la Keeley (2007), quien define al capital humano como la mezcla de aptitudes innatas al individuo y el conjunto de aprendizajes que va adquiriendo a lo largo de su vida mediante la capacitación y educación recibida. A manera de complemento, Morales, Jacobo, Ochoa e Ibarra (2020) señalan que este concepto alude a las habilidades, conocimientos y actitudes del personal, y enfatizan en la influencia que estos elementos tienen en el desempeño organizacional. Flores, Álvarez y Pedraza (2020), por otra parte, mencionan que el capital humano refiere a una serie de activos intangibles que son propiedad exclusiva de cada individuo, indispensables para el cumplimiento de las actividades asignadas (por ejemplo, intelecto, creatividad, know-how).

Las fuentes anteriormente citadas también han hecho evidente la amplia gama de elementos incorporados al término de capital humano, todos ellos orientados a generar ventajas competitivas siempre que se realice una adecuada gestión parte de la alta dirección. Al respecto de este último punto, diversos estudios científicos han corroborado la incidencia significativa que estos componentes poseen sobre el desempeño de la organización (Escandón, Arias y Salas, 2012; Pardo y Díaz, 2014; Villegas, Hernández y Salazar, 2017). La relevancia de continuar con investigaciones donde se analicen las cualidades que posee el capital humano no es otra que la de identificar aquellas que aportan más valor a los procesos y servicios, y en última instancia, la de implementar buenas prácticas organizacionales que coadyuven a perfeccionar las competencias y habilidades que así se requieran con la finalidad de dar respuesta oportuna a la nueva era, tan competitiva y compleja (Tobón, 2015).

Ahora bien, es igualmente importante mencionar que investigaciones empíricas han propuesto una serie de factores bajo los cuales es posible medir el constructo de capital humano en términos científicos. Ejemplo de ello es el estudio desarrollado por Ruggeri y Yu (2000), quienes destacan el potencial, adquisición y disponibilidad como factores determinantes que integran esta variable. Por su parte, Gómez (2016) determinó que el capital humano está determinado por cinco factores principales: capacitación, entorno, especialización, experiencia y política.

Mariño, Rodríguez y Rubio (2013), por otro lado, apuntan que la variable en cuestión está determinada por los factores motivación, experiencia, satisfacción y formación y desarrollo, siguiendo los resultados estadísticos obtenidos en su investigación. Mientras que De Castro, Alama, Navas y López (2009) señalan que la experiencia y las habilidades, la 

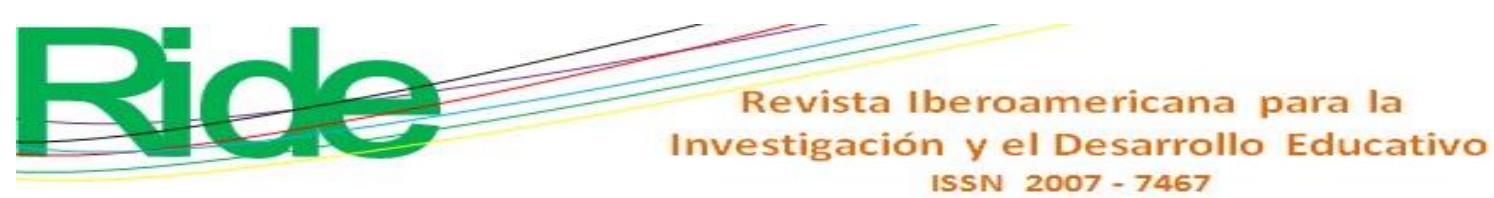

motivación y el desarrollo profesional y la permanencia son los tres factores que agrupan la variable de capital humano. Otros autores como Bontis (1998), Crema y Verbano (2014), Sánchez, Melián, y Hormiga (2007) y Vasconcelo (2017) afirman que el capital humano se conforma básicamente de tres componentes: la colaboración, la creatividad y las competencias, según el análisis de sus indagaciones.

Cabe señalar que esta última clasificación del capital humano (colaboración, creatividad y competencias) ha presentado gran aceptación por la comunidad académicocientífica: estos factores han sido recurrentes en los estudios abordados bajo esta línea de investigación (Chen, Zhu y Xie, 2004; Edvinsson y Malone, 1999; Euroforum, 1998; Rodríguez y Rubio, 2006; Roos, Roos, Dragonetti y Edvinsson, 2001; Shih, Chang y Lin, 2010), motivo por el cual se toman también aquí de referente a efecto de valorar la variable de capital humano en las IES. La definición de estos factores se presenta en la tabla 1.

Tabla 1. Factores del capital humano

\begin{tabular}{|l|l|}
\hline \multicolumn{1}{|c|}{ Factor } & \multicolumn{1}{|c|}{ Definición } \\
\hline Competencias & $\begin{array}{l}\text { Hace referencia a la capacidad que tienen las personas para responder } \\
\text { efectivamente a las exigencias del trabajo, según su aprendizaje, cualidades, } \\
\text { habilidades y aptitudes adquiridas (Ruíz, Jaraba y Romero, 2005). }\end{array}$ \\
\hline Creatividad & $\begin{array}{l}\text { Refiere a la facilidad con la que los individuos de una organización resuelven } \\
\text { conflictos y desarrollan soluciones para las negociaciones, la agilidad con la } \\
\text { que generan ideas y conocimiento nuevo, y la forma en la que intercambian } \\
\text { información con los demás miembros de la organización (Woodman, Sawyer } \\
\text { y Griffin, 1993). }\end{array}$ \\
\hline Colaboración & $\begin{array}{l}\text { Se concibe como el elemento del capital humano que refleja los lazos de } \\
\text { compañerismo y confianza que tienen los integrantes de la institución para } \\
\text { trabajar en equipo, compartir recursos, resolver problemas en conjunto y } \\
\text { mantener una buena comunicación con los directivos de la compañía (Felício, } \\
\text { Couto y Caiado, 2014). }\end{array}$ \\
\hline
\end{tabular}

Fuente: Elaboración propia con base en los autores citados 


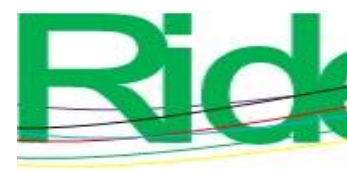

Revista Iberoamericana para la Investigación y el Desarrollo Educativo ISSN $2007-7467$

Al hablar de competencias en el sector educativo, Carro, Hernández, Lima y Corona (2016), Hernández (2017), Herrera (2017), Martínez, Hernández y Gómora (2016) comentan que la determinación de las competencias a desarrollar en los alumnos es uno de los elementos fundamentales que toda IES establece en sus planes y programas de estudio. Sin embargo, ante el actual escenario académico, es importante que tanto el personal docente como administrativo posean también las competencias necesarias para conducir a la organización hacia la eficiencia educacional, así como abordar estudios donde se analicen las áreas de oportunidad respecto a este competente a fin de optimizar sus atributos en beneficio del sector educación.

Mientras que, en lo que se refiere a la creatividad, Elisondo (2015), Hernández, Alvarado y Luna (2015) y Jiménez (2019) afirman que toda IES que cuente con capital humano creativo y competente para innovar los procesos de enseñanza-aprendizaje e implementar metodologías de trabajo más colaborativas entre los actores principales de la educación definitivamente alcanzará un desempeño superior en su quehacer institucional.

Y en cuanto al factor de colaboración y su impacto en las IES, Krichesky y Murillo (2018), Martín y Morales (2013), Montero (2011), Moreno (2006) señalan que dentro de los centros educativos de educación superior la colaboración es uno de los aspectos clave para impulsar los procesos de mejora en la enseñanza, puesto que permite generar una visión compartida, lo que facilita la toma de decisiones y, sobre todo, la implementación de las líneas de acción que favorezcan el aprendizaje de los estudiantes.

En definitiva, las competencias, la creatividad y la colaboración del capital humano son elementos importantes que ejercen influencia en el desempeño de las IES, organizaciones que tienen como propósito principal la producción y generación de conocimiento, donde el intelecto del personal representa el activo más preciado (Cuentas, 2018; Durán, 2016). De ahí la decisión de considerar cada uno de ellos en la presente investigación, a fin de determinar el nivel de influencia que ejercen en el desempeño organizacional de las IES, específicamente en la faceta de desempeño contextual, la cual se describe a continuación. 


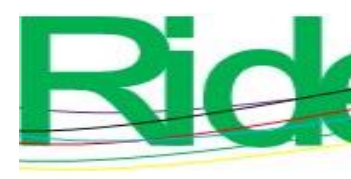

Revista Iberoamericana para la

Investigación y el Desarrollo Educativo

ISSN $2007-7467$

\section{Desempeño laboral: definiciones y facetas de medición}

De acuerdo con Díaz, Díaz, Isla, Hernández y Rosales (2012), el desempeño es uno de los temas que mayor avance ha presentado en el campo de estudio de la psicología organizacional, puesto que la información que se genera a través de su análisis representa el punto de partida para otros procedimientos organizacionales, tal y como la capacitación del personal, el reconocimiento laboral, los estímulos y recompensas y la toma de decisiones, entre otros (Ramos, Barrada, Fernández y Koopmans, 2019).

Fogaca, Barbosa, Campos, Pereira y Coelho (2018) argumentan que el desempeño engloba todos los comportamientos que un empleado presenta al hacer su trabajo. Chiavenato (2000) es un poco más preciso y menciona que, en efecto, el desempeño alude a las acciones o comportamientos de los trabajadores, pero no se trata de cualquier tipo de acción o comportamiento, sino solo aquellos que resultan esenciales para el cumplimiento de los objetivos establecidos por la organización.

Por su parte, Milkovich y Bourdeau (1994) dicen que el desempeño es la forma en cómo el personal de la organización da cumplimiento a los requerimientos de las actividades asignadas. Mientras que Robbins (2004) establece que el desempeño apunta a la capacidad que tiene el personal para coordinar y organizar sus actividades.

$\mathrm{Al}$ analizar estas definiciones es posible concluir que el desempeño hace referencia a cualquier respuesta o acción de un individuo que vaya encaminada al logro de objetivos organizacionales. Por supuesto, está vinculado con aspectos que tienen que ver con la calidad, cantidad, costo y tiempo que emplea una persona para cumplir una función (Araújo y Guedes, 2016; Marchezi, von Borell, Matos y dos Santos, 2019). Además, aplica criterios de cooperación, responsabilidad, conocimiento, asistencia y supervisión a fin de garantizar la consecución de las metas y el uso eficiente de los recursos disponibles (Chiang y San Martín, 2015).

Ahora bien, Ramos et al. (2019) comentan que existen diversas maneras a través de las cuales puede ser medible el desempeño en las instituciones públicas y privadas, ello dependiendo del interés y propósito del análisis que se desee realizar. Teniendo en cuenta lo anterior, Borman y Motowidlo (1993), Coleman y Borman (2000) y Conway (1999) realizaron una taxonomía de las distintas dimensiones que contempla el desempeño gerencial, y lograron validar un modelo que determina las tres facetas principales en la 


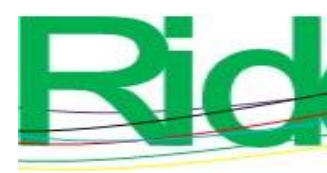

Revista Iberoamericana para la Investigación y el Desarrollo Educativo ISSN 2007 - 7467

operacionalización de este constructo, a saber: desempeño de tarea, desempeño contextual y conductas contraproductivas (tabla 2).

Tabla 2. Facetas del desempeño

\begin{tabular}{|l|l|}
\hline \multicolumn{1}{|c|}{ Faceta } & \multicolumn{1}{|c|}{ Definición } \\
\hline Desempeño de & $\begin{array}{l}\text { Contempla la eficiencia del personal para dar cumplimiento a las funciones } \\
\text { técnicas que le son asignadas por la organización. Se enfoca en evaluar la } \\
\text { contribución del empleado en un área específica relacionada con su puesto } \\
\text { de trabajo y las habilidades que esta requiere (Basoredo, 2011; Campbell, } \\
\text { McHenry y Wise, 1990). }\end{array}$ \\
\hline contextual & $\begin{array}{l}\text { También llamado desempeño cívico. Evalúa las conductas de apoyo y } \\
\text { solidaridad que expresan los empleados hacia el logro de las metas } \\
\text { institucionales, más allá de las obligaciones técnicas de su puesto de trabajo, } \\
\text { ayudando a la creación de entornos de trabajo favorables (Borman y } \\
\text { Motowidlo, 1993; Borman, 2004; Delgado et al., 2018). }\end{array}$ \\
\hline Conductas & $\begin{array}{l}\text { Refiere a comportamientos desfavorables que incumplen con la normativa } \\
\text { institucional y afectan el bienestar de la organización y de los colaboradores } \\
\text { que la integran (Sackett, 2002; Spector, Fox, Penney, Bruursema, Goh y } \\
\text { Kessler, 2006). }\end{array}$ \\
\hline
\end{tabular}

Fuente: Elaboración propia con base en los autores citados

Cabe destacar que el desempeño contextual, a diferencia del desempeño de tareas y conductas contraproductivas, es una variable que trasciende a todas los niveles de la organizacional, puesto que valora aspectos que están más relacionados con las conductas motivacionales, es decir, es más implícito que explícito en el actuar del personal (Gorriti, 2007). Esto le ha permitido ocupar un papel importante en el estudio de la psicología y el comportamiento organizacional (Bilal, Bahadar, Yasir y Mateen 2015; Kalia y Bhardwaj, 2019). La medición del desempeño contextual aporta información útil para la toma de decisiones estratégicas, ya que dicha información permite conocer las tendencias de comportamiento que los empleados experimentan en el contexto general de la institución, más allá del área de trabajo. 


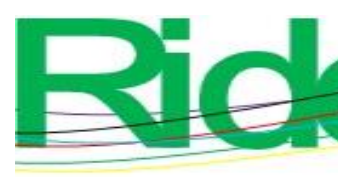

Revista Iberoamericana para la Investigación y el Desarrollo Educativo ISSN $2007-7467$

Específicamente en las IES, Bernasconi (2010) señala que los estándares de desempeño no solo deben contemplar los perfiles profesionales y el cumplimiento de la docencia, sino que se deben considerar los diversos roles que desempeña el personal en términos de enseñanza, carga administrativa y política interna, lo cual requiere de una evaluación holística que contemple el desempeño del personal a nivel contextual. Asimismo, Bilal et al. (2015) establecen que examinar el desempeño contextual de los trabajadores de la educación permite tener una visión integral de las conductas y comportamientos que inciden en el logro de objetivos de manera eficiente y eficaz, puesto que, a través del análisis realizado, se logran identificar áreas de oportunidad relacionadas con el compromiso del personal más allá de sus obligaciones laborales.

Por otra parte, Vilcamichi (2017) reconoce que valorar el desempeño de la ciudadanía que integra las IES a nivel contextual genera importantes beneficios para el adecuado desarrollo de las actividades educativas; ello debido a que, entre otros aspectos, el desempeño contextual define el clima de trabajo bajo el cual se practican los procesos de enseñanzaaprendizaje, lo que facilita el apoyo colaborativo entre el personal y el reforzamiento de conductas positivas; en suma, brinda las condiciones propicias para la mejora continua de la institución.

Partiendo de estas aseveraciones, es posible concluir que evaluar el desempeño contextual representa un componente importante que permitirá a las IES seguir avanzando hacia las nuevas exigencias del entorno, hacia la transformación y modernización. No obstante, hay que recordar que a fin de lograr un eficiente desempeño contextual es importante asegurar, antes que nada, que el personal que conforma la ciudadanía organizacional posea las competencias, la creatividad y los lazos de colaboración requeridos para obtener los resultados esperados, puesto que la investigación científica reconoce la importancia de estos componentes del capital humano como parte fundamental en los sistemas de medición del desempeño (Gates y Langevin, 2013).

En este sentido, la presente investigación plantea como modelo de investigación la existencia de una relación lineal entre los factores de competencias, creatividad y colaboración respecto al desempeño contextual de IES (figura 1). Las hipótesis son las siguientes: 


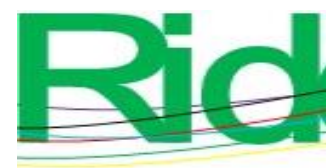

Revista Iberoamericana para la Investigación y el Desarrollo Educativo ISSN 2007 - 7467

- H1. Las competencias del capital humano tienen influencia positiva y significativa en el desempeño contextual de las IES.

- $\quad$ H2. La creatividad del capital humano tiene influencia positiva y significativa en el desempeño contextual de las IES.

- H3. La colaboración del capital humano tiene influencia positiva y significativa en el desempeño contextual de las IES.

Figura 1. Modelo de investigación

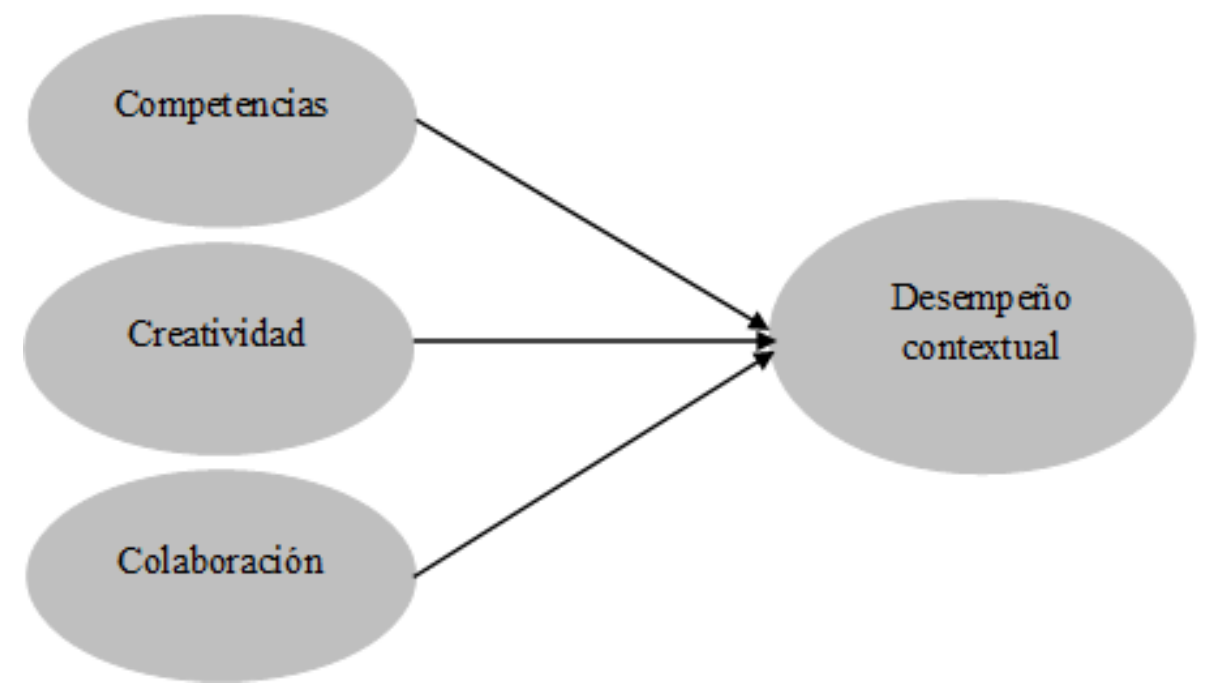

Fuente: Elaboración propia

\section{Método}

Para contrastar las hipótesis de investigación previamente descritas, el diseño de este estudio se caracteriza por ser de enfoque cuantitativo (Bernal, 2010; Hernández, Fernández y Baptista, 2014), tal como se detalla en la tabla 4. La técnica de recolección de datos fue a partir de un cuestionario conformado por tres secciones principales: 1) datos generales de los encuestados, 2) valoración de los factores de competencias, creatividad y colaboración del capital humano y 3 ) evaluación del desempeño contextual.

Para el diseño del cuestionario se efectuó, en primera instancia, la revisión documental de estudios previos que han abordado el análisis de las variables contempladas en la presente investigación, identificando con ello la descripción conceptual y operacional de cada constructo. Para el caso de los factores de competencias, creatividad y colaboración, 


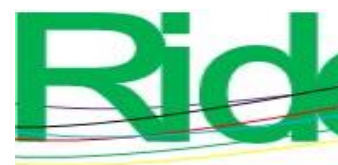

Revista Iberoamericana para la Investigación y el Desarrollo Educativo ISSN $2007-7467$

fueron los estudios de Bontis (1998), Crema y Verbano, (2014), Huang y Jim (2010) y Vasconcelo (2017) los que se tomaron como referentes, mientras que para la variable de desempeño contextual se seleccionaron los reactivos contemplados en la escala propuesta por Coleman y Borman (2000), previamente adaptada y validada al sector público por Díaz et al. (2012).

La decisión de tomar como referente el aporte de estos autores para el diseño del cuestionario se debe a que las escalas propuestas cumplen con los criterios y características requeridos para medir las variables de competencias, creatividad, colaboración y desempeño contextual, puesto que los resultados obtenidos en sus investigaciones avalan altos índices de fiabilidad y validez en los ítems examinados para la medición de estos factores. No obstante, es importante mencionar que, a fin de validar el contenido del cuestionario diseñado, se solicitó a investigadores expertos del cuerpo académico "Gestión pública y empresarial” de la Universidad Autónoma de Tamaulipas que emitieran su juicio respecto a la conformación de la escala, su estandarización y consistencia de reactivos; así, los expertos realizaron observaciones que contribuyeron a la adecuación en redacción y presentación de los enunciados. De ahí que el instrumento de medición quedó conformado por 15 reactivos, a partir de los cuales se abordó el análisis de las variables independientes de creatividad, competencias y colaboración, distribuidos de forma equitativa entre estos tres componentes, mientras que para la variable dependiente de desempeño contextual el número de ítems valorados corresponde a 27 enunciados (tabla 3 ). 


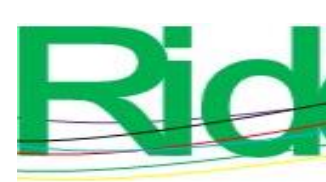

Revista Iberoamericana para la Investigación y el Desarrollo Educativo ISSN 2007 - 7467

Tabla 3. Medición de las variables de estudio

\begin{tabular}{|c|c|c|}
\hline $\begin{array}{c}\text { Variable de } \\
\text { estudio }\end{array}$ & Ítems valorados & Referente \\
\hline Cre: & $\begin{array}{l}\text { 1) El personal de esta institución es capaz de desarrollar } \\
\text { nuevas ideas y conocimiento. } \\
\text { 2) El personal de esta institución es brillante y creativo. } \\
\text { 3) El personal de esta institución hace frente a las } \\
\text { dificultades con eficiencia. } \\
\text { 4) El personal de esta institución se centra en ofrecer un } \\
\text { servicio de calidad. } \\
\text { 5) El personal de esta institución tiene un bajo índice de } \\
\text { rotación. }\end{array}$ & $\begin{array}{l}\text { Bontis } \\
\text { (1998), } \\
\text { Crema y } \\
\text { Verbano, } \\
\text { (2014), } \\
\text { Huang y Jim } \\
\text { (2010) y } \\
\text { Vasconcelo } \\
\text { (2017). }\end{array}$ \\
\hline Compe & $\begin{array}{l}\text { 1) El personal de esta institución aprende continuamente de } \\
\text { otros. } \\
\text { 2) El personal de esta institución cuenta con las } \\
\text { competencias necesarias para el puesto. } \\
\text { 3) El personal de esta institución cuenta con los estudios } \\
\text { profesionales necesarios que demanda su función. } \\
\text { 4) El personal de esta institución es muy profesional. } \\
\text { 5) El personal de esta institución obtiene mejores resultados } \\
\text { cuando trabajan en equipo. }\end{array}$ & $\begin{array}{c}\text { Bontis } \\
\text { (1998), } \\
\text { Crema y } \\
\text { Verbano, } \\
\text { (2014), } \\
\text { Huang y Jim } \\
\text { (2010) y } \\
\text { Vasconcelo } \\
\text { (2017). }\end{array}$ \\
\hline Colaboración & $\begin{array}{l}\text { 1) El personal de esta institución fomenta la confianza y } \\
\text { colaboración en los equipos de trabajo. } \\
\text { 2) El personal de esta institución colabora entre sí para } \\
\text { resolver problemas y desarrollar soluciones de negociación. } \\
\text { 3) El personal de esta institución es capaz de participar en } \\
\text { los programas de flexibilidad laboral. } \\
\text { 4) El personal de esta institución comparte los recursos e } \\
\text { información de los usuarios. } \\
\text { 5) El personal de esta institución colabora con los directivos } \\
\text { en la toma de decisiones. }\end{array}$ & $\begin{array}{c}\text { Bontis } \\
\text { (1998), } \\
\text { Crema y } \\
\text { Verbano, } \\
\text { (2014), } \\
\text { Huang y Jim } \\
\text { (2010) y } \\
\text { Vasconcelo } \\
\text { (2017). }\end{array}$ \\
\hline
\end{tabular}




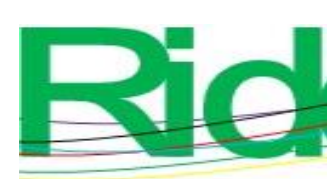

Revista Iberoamericana para la Investigación y el Desarrollo Educativo ISSN 2007 - 7467

\begin{tabular}{|c|c|c|}
\hline $\begin{array}{l}\text { Desempeño } \\
\text { contextual }\end{array}$ & 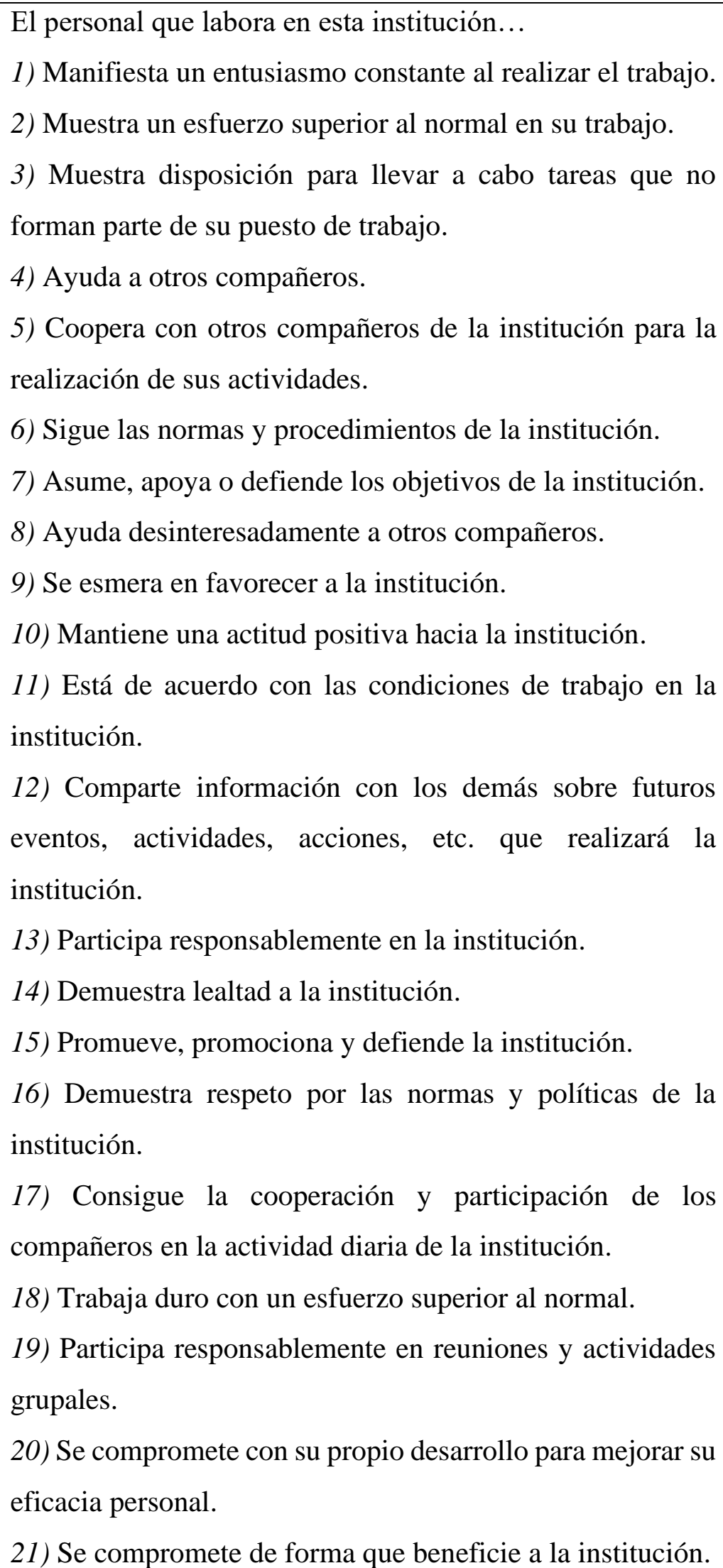 & $\begin{array}{l}\text { Coleman y } \\
\text { Borman } \\
\text { (2000) y Díaz } \\
\text { et al. (2012) }\end{array}$ \\
\hline
\end{tabular}




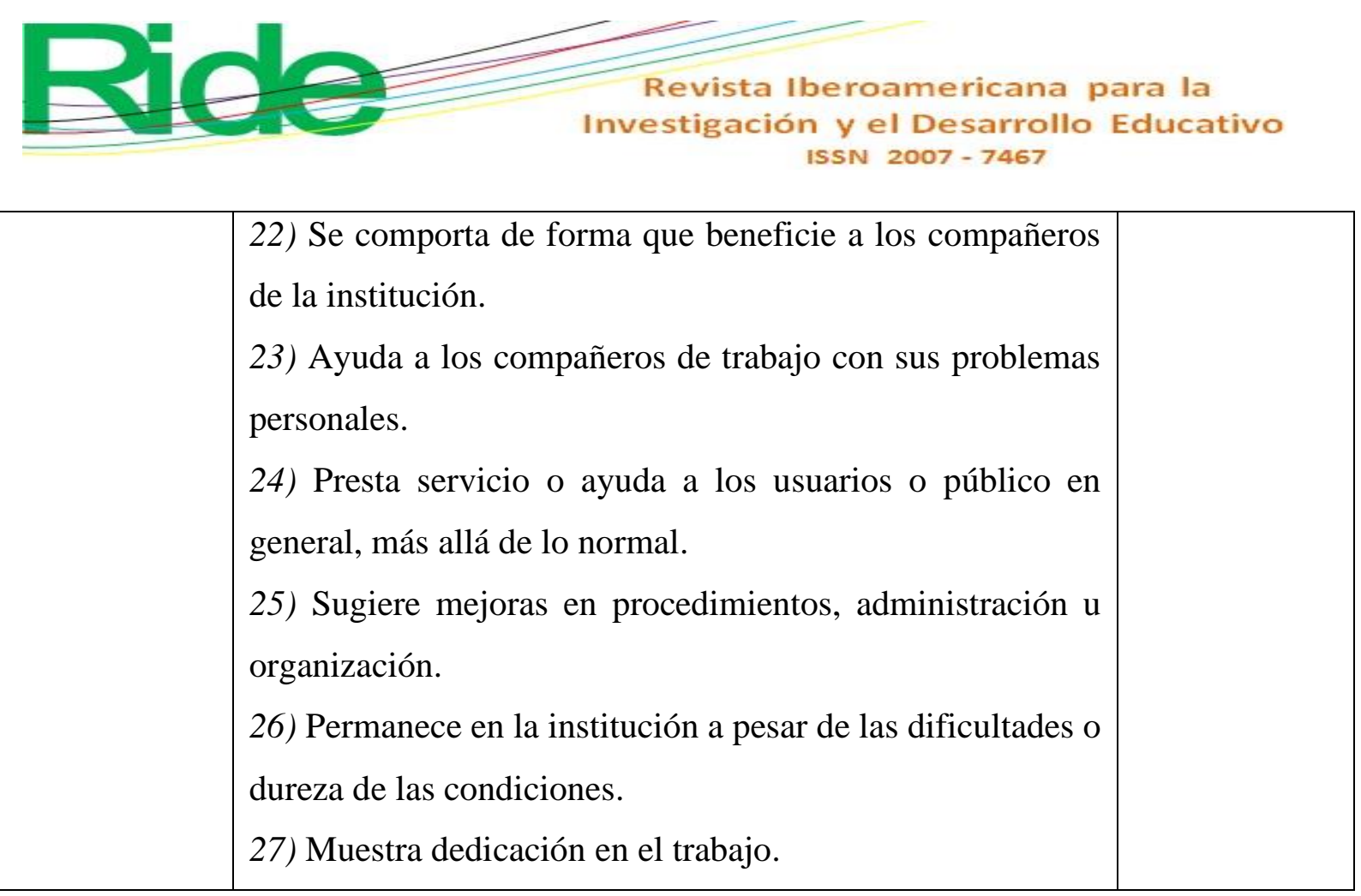

\begin{tabular}{|l|l|}
\hline 22) Se comporta de forma que beneficie a los compañeros \\
de la institución. \\
23) Ayuda a los compañeros de trabajo con sus problemas \\
personales. \\
24) Presta servicio o ayuda a los usuarios o público en \\
general, más allá de lo normal. \\
25) Sugiere mejoras en procedimientos, administración u \\
organización. \\
26) Permanece en la institución a pesar de las dificultades o \\
dureza de las condiciones. \\
27) Muestra dedicación en el trabajo.
\end{tabular} \mid

\section{Fuente: Elaboración propia}

Continuando con el proceso de validación de constructo del cuestionario, estadísticamente se empleó el análisis factorial a través del cual se logró validar la estructura subyacente de las variables analizadas (Kaiser, Meyer y Olkin [KMO] > 0.70; ji al cuadrado $\neq 0$; significancia $<0.05$; carga factorial >0.60). El siguiente paso consistió en el análisis de los datos recopilados. En este paso se utilizó la técnica de estadística descriptiva con la finalidad de conocer el perfil de los encuestados y la percepción de los participantes respecto a la valoración de los constructos de estudio. Seguido de ello, a fin de determinar la incidencia de las variables independientes sobre el desempeño contextual, se efectuó el análisis de correlación mediante el cual se logró identificar la asociación estadística entre los factores de competencias, creatividad, colaboración y el desempeño contextual. Y finalmente, para dar respuesta al objetivo e hipótesis de investigación, se llevó a cabo el análisis de regresión lineal (tabla 4). 


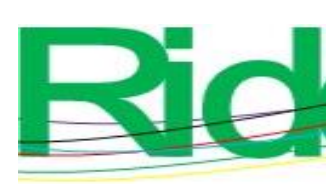

Revista Iberoamericana para la Investigación y el Desarrollo Educativo ISSN $2007-7467$

Tabla 4. Ficha técnica de investigación

\begin{tabular}{|c|c|}
\hline Diseño de investigación & $\begin{array}{l}\text { Enfoque cuantitativo, diseño no experimental, } \\
\text { corte transversal, alcance descriptivo- } \\
\text { correlacional-explicativo }\end{array}$ \\
\hline Sujetos de estudio & Personal docente y administrativo adscrito a IES \\
\hline Muestra & No probabilística de 95 participantes \\
\hline Ámbito geográfico & Tamaulipas, México \\
\hline Técnica de recolección de datos & Cuestionario \\
\hline Variables de estudio & $\begin{aligned} \text { Independiente }= & \text { competencias, colaboración y } \\
& \text { creatividad } \\
\text { Dependiente }= & \text { desempeño contextual }\end{aligned}$ \\
\hline Técnicas de análisis de datos & $\begin{array}{l}\text { Estadística descriptiva } \\
\text { Análisis factorial } \\
\text { Análisis de correlación } \\
\text { Regresión múltiple lineal }\end{array}$ \\
\hline
\end{tabular}

Fuente: Elaboración propia

\section{Resultados}

Como se ha comentado previamente, la muestra de participación en esta investigación estuvo representada por 95 encuestados, $40 \%$ de sexo masculino y $60 \%$ femenino, de los cuales $41 \%$ corresponde a personal con cargo administrativo y $59 \%$ a docentes.

Por otra parte, de acuerdo con los datos proporcionados, se observó que la escolaridad predominante en los encuestados es de nivel licenciatura (52\%), seguido del personal que cuenta con estudios de posgrado ( $26 \%$ y, por último, quienes poseen un nivel académico de nivel preparatoria o secundaria (22\%). Asimismo, a través del análisis descriptivo se identificó que $17 \%$ lleva menos de cinco años laborando en la IES a la que actualmente se encuentran adscritos, $29 \%$ tiene entre 6 y 10 de antigüedad laboral, $22 \%$ dice tener entre 11 y 15 años, $13 \%$ se encuentra entre 16 a 20 años de servicio para su IES y el $19 \%$ restante comenta tener más de 20 años de antigüedad en la organización. 


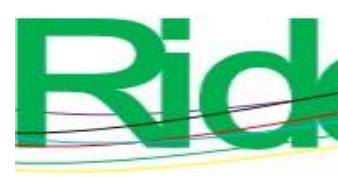

Revista Iberoamericana para la
Investigación y el Desarrollo Educativo
ISSN $2007-7467$

Es de destacar que se contó con una distribución equitativa en la recolección de los datos según el perfil de los encuestados, lo cual permite tener una visión objetiva respecto a la valoración de las variables analizadas. Al respecto, $76 \%$ de los participantes opina que el personal de la IES donde labora cuenta con las competencias necesarias para el desempeño de su función; $80 \%$ dice estar de acuerdo con la creatividad de sus compañeros, y $60 \%$ afirma que los integrantes de la institución siempre están dispuestos a colaborar en la toma de decisiones y actividades requeridas por la alta dirección. Estos porcentajes delinean una evaluación favorable a las variables de competencias, colaboración y creatividad.

De igual forma, se destaca que para el desempeño contextual el promedio de respuestas determinó que $84 \%$ de los encuestados asegura que el personal adscrito a su centro de trabajo manifiesta un adecuado desempeño contextual hacia la IES donde laboran. Es decir, según la mayoría de las opiniones, los empleados muestran dedicación a su trabajo, se comprometen con la institución, realizan esfuerzo superior para mejorar su eficacia personal, mantienen una actitud positiva, apoyan y defienden los objetivos de su organización y ayudan a sus compañeros, entre otros elementos evaluados del desempeño contextual que favorecen también la valoración de esta variable.

A partir de estos hallazgos se concluye que tanto las variables de competencias, colaboración y creatividad como el desempeño contextual cuentan con opiniones altamente favorables por parte de los encuestados. Huelga decir que dichos porcentajes positivos se determinaron mediante estadística descriptiva.

Una vez analizada la apreciación del personal respecto a estas variables, el siguiente paso consistió en identificar el grado de asociación que existe entre ellas a fin de identificar, a través del análisis de correlación, si existe relación positiva entre los constructos de estudio y posteriormente obtener estimaciones más precisas mediante la técnica de regresión lineal. Así pues, la tabla 5 detalla los resultados obtenidos de las correlaciones realizadas. Allí es posible observar que, con un nivel de confianza de $95 \%$, las competencias, colaboración y creatividad del capital humano se asocian positivamente con el desempeño contextual. 


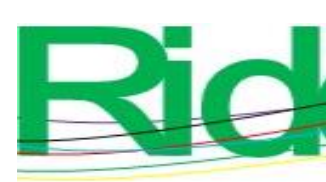

Revista Iberoamericana para la Investigación y el Desarrollo Educativo ISSN 2007-7467

Tabla 5. Análisis de correlación

\begin{tabular}{|l|l|c|}
\hline \multicolumn{2}{|l|}{} & Desempeño contextual \\
\hline \multirow{4}{*}{ Creatividad } & Correlación de Pearson & $0.556^{* *}$ \\
\cline { 2 - 3 } & Sig. (bilateral) & 0.000 \\
\cline { 2 - 3 } & $\mathrm{N}$ & 95 \\
\hline \multirow{4}{*}{ Competencias } & Correlación de Pearson & $0.592^{* *}$ \\
\cline { 2 - 3 } & Sig. (bilateral) & 0.000 \\
\cline { 2 - 3 } & $\mathrm{N}$ & 95 \\
\hline & Correlación de Pearson & $0.600^{* *}$ \\
\cline { 2 - 3 } & Sig. (bilateral) & 0.000 \\
\cline { 2 - 3 } & N & 95 \\
\hline
\end{tabular}

Fuente: Elaboración propia

De acuerdo con los resultados observados en la tabla 5 es posible definir que existe una relación positiva y significativa entre la creatividad, competencias y colaboración respecto al desempeño contextual en IES, puesto que los datos resultantes indican que a medida que aumente cada variable independiente el desempeño contextual también se verá favorecido en su incremento (entre más se aproxime a uno el coeficiente de correlación mayor será el grado de relación entre estos factores).

Es decir, a nivel correlacional, se identifica que las capacidades creativas, las competencias adquiridas y los lazos de colaboración del personal docente y administrativo participes en esta investigación ejercen una asociación significativa en el desempeño contextual de estos empleados, puesto que, al sentirse con las cualidades intelectuales necesarias para realizar su trabajo, este personal adquiere mayor confianza, conocimiento y disposición para apoyar al logro de los objetivos organizacionales, manifestar entusiasmo hacia sus labores educativas, ayudar a otros compañeros, participar en actividades académicas y, principalmente, otorgar un servicio de calidad a los educandos, por lo que a medida que dichas competencias, creatividad y colaboración aumenten su desempeño contextual también se incrementará recíprocamente, lo cual sugiere se implementen buenas prácticas de gestión del capital humano al interior de las IES con la finalidad de optimizar las cualidades de cada individuo, contribuyendo así a un mejor desempeño contextual. 

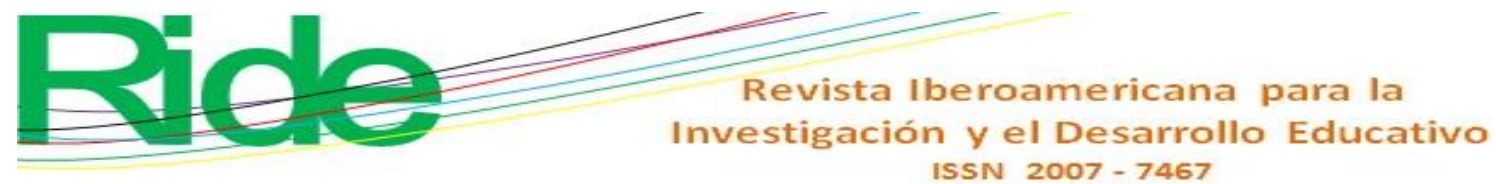

Ahora bien, con la finalidad de robustecer los resultados obtenidos del análisis de correlación, enseguida se muestran los modelos de regresión lineal generados para predecir la influencia que cada una de las variables independientes tiene sobre el desempeño contextual, tal como se plantea en el objetivo central de esta investigación. Como primer modelo de regresión se analizó la incidencia entre competencias y desempeño contextual:

$$
\begin{gathered}
\gamma=\beta 0+\beta 1 \chi 1+\varepsilon \\
\text { Desempeño contextual }=\beta 0+\beta 1(\text { competencias })+\varepsilon
\end{gathered}
$$

$\mathrm{Y}$ los resultados obtenidos detallan de manera positiva y significativa $(p<0.05)$ que el desempeño contextual es explicado en $35 \%\left(R^{2}\right)$ por las competencias que el personal de las IES posee, es decir, coadyuvan de manera eficiente al logro de los objetivos organizacionales. Asimismo, se identifica en este primer modelo que $\beta 1$ obtiene un valor de 0.592, lo cual apunta a que, por cada punto de incremento en las competencias del personal, el desempeño contextual también aumentará su valor en 0.592 puntos; así, se comprueba la relación lineal positiva que existe entre estas dos variables de estudio, hallazgo que permite aceptar la H1 de investigación (tabla 6).

Como segundo modelo de regresión se plantea la incidencia entre la creatividad del capital humano y el desempeño contextual, representado por la siguiente ecuación:

$$
\begin{gathered}
\gamma=\beta 0+\beta 1 \chi 2+\varepsilon \\
\text { Desempeño contextual }=\beta 0+\beta 1(\text { creatividad })+\varepsilon
\end{gathered}
$$

En este caso, los resultados obtenidos demuestran estadísticamente que la creatividad de igual forma tiene incidencia positiva en el desempeño contextual: se logró alcanzar un valor para $R^{2}$ de 0.310 , que se traduce en $31 \%$ del desempeño contextual explicado por la creatividad de docentes y administrativos que integran las IES, con un P-valor de 0.000 y una $\beta 1$ de 0.556 (tabla 6), parámetros de medición que hacen posible aceptar la $\mathrm{H} 2$ planteada en esta investigación, debido a que los valores alcanzados a través de este modelo de regresión así lo confirman.

Por último, el modelo que representa la regresión entre la colaboración y el desempeño contextual se presenta a partir de la siguiente ecuación: 


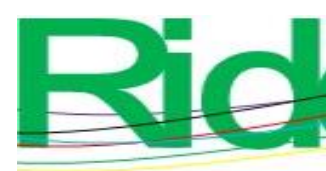

$$
\begin{gathered}
\gamma=\beta 0+\beta 1 \chi 3+\varepsilon \\
\text { Desempeño contextual }=\beta 0+\beta 1(\text { colaboración })+\varepsilon
\end{gathered}
$$

Para este modelo es importante resaltar que, de forma similar a los resultados observados en el análisis de correlación, la variable de colaboración es la que mayor grado de incidencia manifiesta tener sobre el desempeño contextual, puesto que, de acuerdo con el valor obtenido para $R^{2}$, los lazos de colaboración entre trabajadores de las IES explican en $36.1 \%$ su desempeño contextual, hallazgo que se evidencia con los resultados presentados en la tabla 6 , donde además se muestra que el valor correspondiente a $\beta 1$ en esta ecuación es de 0.600 , es decir, por cada punto incremental en la variable de colaboración el desempeño contextual incrementará de forma lineal 0.600 puntos su valor. Así, se acepta la afirmación planteada en la $\mathrm{H} 3$ de este estudio.

Tabla 6. Análisis de regresión lineal

\begin{tabular}{|c|c|c|c|}
\hline Coeficientes de regresión & Competencias & Creatividad & Colaboración \\
\hline$\beta 1$ & 0.592 & 0.556 & 0.600 \\
\hline P-valor & 0.000 & 0.000 & 0.000 \\
\hline$R^{2}$ & 0.350 & .0310 & 0.361 \\
\hline$R^{2}$ ajustado & 0.343 & .302 & 0.354 \\
\hline
\end{tabular}

Fuente: Elaboración propia

En definitiva, los resultados obtenidos a través de los modelos de regresión lineal confirman los datos previamente observados en el análisis de correlación, ello al demostrar estadísticamente que, al existir mayores lazos de compañerismo y confianza entre los empleados de las IES, mayor será el desempeño alcanzado a nivel contextual. Asimismo, al poseer el personal las cualidades, competencias y aptitudes necesarias para el desarrollo de sus actividades, así como la creatividad y agilidad para solucionar problemas y generar nuevo conocimiento, el desempeño contextual será mayor positiva y significativamente, de tal forma que el personal aportará un esfuerzo superior para cumplir con las metas institucionales, más allá de las obligaciones técnicas asignadas a su puesto de trabajo. 


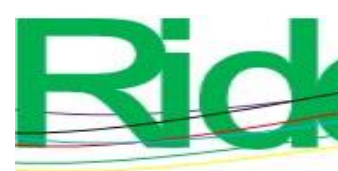

Revista Iberoamericana para la Investigación y el Desarrollo Educativo ISSN 2007-7467

\section{Discusión}

De acuerdo con los resultados obtenidos en este estudio, se ha observado que las cualidades intangibles del capital humano, competencias, creatividad y lazos de colaboración interpersonal, son variables que ejercen influencia positiva y estadísticamente significativa sobre el desempeño contextual (tabla 6), evidencia empírica que permite aceptar las hipótesis de investigación planteadas en la presente indagación.

Específicamente, estos resultados para las IES representan un área de oportunidad para la toma de decisiones efectivas que coadyuven al diseño de buenas prácticas para impulsar el potencial intelectual de docentes y administrativos que forman parte de la ciudadanía organizacional, ello con la finalidad de acrecentar su valor e incidencia en el desempeño de sus funciones a un nivel contextual de la organización. Lo anterior tomando en cuenta que la revisión de literatura (Escandón et al. 2012; Pardo y Díaz, 2014; Villegas et al. 2017) y los modelos estadísticos de regresión aquí analizados confirman la relación lineal que existe entre estas variables de capital humano y el desempeño contextual.

En lo que respecta a la variable de competencias, los resultados expuestos en este estudio encuentran respaldo en las investigaciones previas desarrolladas por Carro et al. (2016), Hernández (2017), Herrera (2017) y Martínez et al. (2016), quienes afirman que las competencias del personal son un activo intangible que generan valor estratégico a las IES al hacer más eficientes los procesos de enseñanza-aprendizaje y elevar la calidad educacional ofertada a los educandos.

Por otra parte, en lo que refiere a la creatividad, Elisondo (2015), Hernández et al. (2015) y Jiménez (2019) postulan que existe una clara relación entre esta variable y el desempeño de las IES. Esto ha quedado demostrado en el análisis de regresión expuesto que forma parte de esta investigación, y a partir del cual es posible afirmar que a mayor capacidad del personal para innovar y ser creativos mejor desempeño contextual se podrá alcanzar al interior de las organizaciones educativas, y así dar respuesta pertinente a las tendencias del mercado y exigencias del entorno social.

Algo análogo sucede con la variable de colaboración. Los datos aquí observados logran evidenciar la influencia positiva y significativa que posee sobre el desempeño contextual. Aún más, este atributo del capital humano es el que mayor grado de incidencia manifiesta tener con la variable dependiente, resultado que fortalece y es fortalecido a la vez 


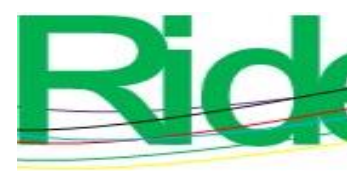

Revista Iberoamericana para la
Investigación y el Desarrollo Educativo ISSN 2007-7467

forjen lazos de compañerismo, apoyo y confianza entre los integrantes de la ciudadanía organizacional.

Aunado a lo anterior, y de acuerdo con la tendencia de respuestas, los constructos analizados en esta investigación lograron obtener en su mayoría opiniones favorables por parte de los encuestados, lo cual se traduce en la aceptación de que los empleados de las IES participantes cuentan con las competencias, creatividad y colaboración requeridos para el desempeño de sus funciones, más allá de su puesto de trabajo. Sin embargo, es recomendable seguir fortaleciendo estas cualidades mediante líneas de acción que coadyuven a la implementación de buenas prácticas de gestión del capital humano en beneficio de la institución, los alumnos y los propios trabajadores de la educación, por lo que los datos observados en esta investigación representan el punto de partida para la toma de decisiones estratégicas por parte de los directivos académicos a fin de acrecentar su valor a los procesos de enseñanza-aprendizaje.

\section{Futuras líneas de investigación}

De acuerdo con los hallazgos encontrados en la presente investigación y tomando en consideración sus alcances y limitaciones, es importante comentar que existen aportes interesantes que pueden ser abordados por la comunidad científica en futuros estudios, ello con la finalidad de reforzar los datos aquí observados bajo nuevas perspectivas e interpretaciones. Como primera propuesta se sugiere el análisis de relación entre las competencias, creatividad y colaboración respecto a las variables de desempeño de tarea y conductas contraproductivas, puesto que estas facetas de desempeño no fueron examinadas aquí por el alcance planificado primariamente, pero que, de ser analizadas, podrían sin duda aportar resultados interesantes para la toma de decisiones y diseño de estrategias en el sector educativo. Por otra parte, se visualiza también como futura línea de investigación analizar el efecto que tiene la personalidad de los individuos en el desempeño contextual, esto bajo la premisa de que, adicional a las cualidades intelectuales de competencias, creatividad y colaboración, las características psíquicas de una persona son también un factor determinante en el desempeño que estos puedan lograr en su campo laboral, por lo que su estudio coadyuvará al establecimiento de buenas prácticas para la gestión de quienes conforman la ciudadanía organizacional. 


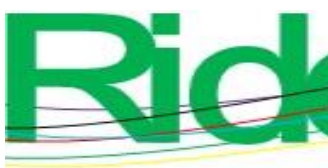

Revista Iberoamericana para la Investigación y el Desarrollo Educativo ISSN $2007-7467$

\section{Referencias}

Araújo, A. C. and Guedes, S. M. (2016). Performance and affects in group problem-solving. Journal of Work and Organizational Psychology, 32(1), 47-54. Retrieved from https://doi.org/10.1016/j.rpto.2015.09.001.

Asiaei, K. and Jusoh, R. (2015). A multidimensional view of intellectual capital: the impact on organizational performance. Management Decision, 53(3), 668-697. Retrieved from https://doi.org/10.1108/MD-05-2014-0300.

Basoredo, C. (2011). Una perspectiva y una forma de explicar la competencia en el contexto del desempeño de las tareas. Anales de Psicología, 27(2), 457-472.

Bernal, C. (2010). Metodología de la investigación: para administración, economía, humanidades y ciencias sociales. Colombia: Pearson Educación.

Bernasconi, A. (2010). La apoteosis del investigador y la institucionalización de la profesión académica. Estudios sobre Educación, 19, 139-163.

Bilal, H., Bahadar, S., Yasir, M. and Mateen, A. (2015). Employee engagement and contextual performance of teaching faculty of private universities. Journal of Managerial Sciences, 9(1), 81-88.

Bontis, N. (1998). Intellectual capital: an exploratory study that develops measures and models. Management Becision, 36(2), 63-76. https://doi.org/10.1108/00251749810204142

Bontis, N., Chong, W. C. and Richardson, S. (2000). Intellectual capital and business performance in Malaysian industries. Journal of Intellectual Capital, 1(1), 85-100. Retrieved from https://doi.org/10.1108/14691930010324188.

Borman, W. C. (2004). The Concept of Organizational Citizenship. Current Directions in Psychological Science, 13(6), 238-241. Retrieved from https://doi.org/10.1111/j.0963-7214.2004.00316.x

Borman, W. C. and Motowidlo, S. J. (1993). Expanding the criterion domain to include elements of contextual performance. In Schmitt, N. and Borman, W. C. (eds.), Personnel Selection in the Organization (pp. 71-98). San Francisco, United States: Jossey-Bass. 


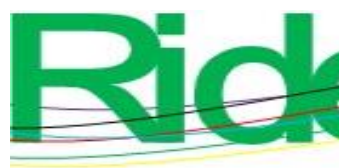

Revista Iberoamericana para la Investigación y el Desarrollo Educativo ISSN $2007-7467$

Campbell, J. P., McHenry, J.J. and Wise, L. L. (1990). Modeling job performance in a population of jobs. Personnel Psychology, 43(2), 313-575. Retrieved from https://doi:10.1111/j.1744-6570.1990.tb01561.x

Carro, A., Hernández, F., Lima, J. A. y Corona, M. M. (2016). Formación profesional y competencias docentes en el estado de Tlaxcala. Educación, 25(49), 7-28. Recuperado de https://dx.doi.org/10.18800/educacion.201602.001

Chen, J., Zhu, Z. and Xie, H. Y. (2004). Measuring intellectual capital: a new model and empirical study. Journal of Intellectual Capital, 5(1), 195-212. Retrieved from https://doi.org/10.1108/14691930410513003

Crema, M., y Verbano, C. (2014). Managing Intellectual Capital in Italian Manufacturing SMEs. Creativity and Innovation Management, 25(3), 408-421. https://doi.org/10.1111/caim.12074

Chiang, M. M. y San Martín, N. J. (2015). Análisis de la satisfacción y el desempeño laboral en los funcionarios de la municipalidad de Talcahuano. Ciencia y Trabajo, 17(54), 159-165. Recuperado de http://dx.doi.org/10.4067/S0718-24492015000300001

Chiavenato, I. (2000). Administración de recursos humanos. México: McGraw Hill.

Coleman, I. and Borman, C. (2000). Investigating the Underlying Structure of the Citizenship Performance Domain. Human Resource Management Review, 10(1), 25-44. Retrieved from https://doi.org/10.1016/S1053-4822(99)00037-6

Conway, J. M. (1999). Distinguishing contextual performance from task performance for managerial jobs. Journal of Applied Psychology, 84(1), 3-13. Retrieved from https://doi.org/10.1037/0021-9010.84.1.3

Cuentas, S. C. (2018). La gestión del capital humano en una unidad académica de educación superior. Educación, 27(53), 57-72. Recuperado de https://doi.org/10.18800/educacion.201802.004

De Castro, G. M., Alama, E. M., Navas, J. E. y López, P. (2009). El papel del capital intelectual en la innovación tecnológica. Una aplicación a las empresas de servicios profesionales de España. Cuadernos de Economía y Dirección de la Empresa, 12(40), 83-110. Recuperado de https://doi.org/10.1016/S1138-5758(09)70043-X

Delgado, N., Hernández, E., Rosales, C., Díaz, L., Isla, R. and Díaz, D. (2018). Contextual Performance in Academic Settings: The Role of Personality, Self-efficacy, and 

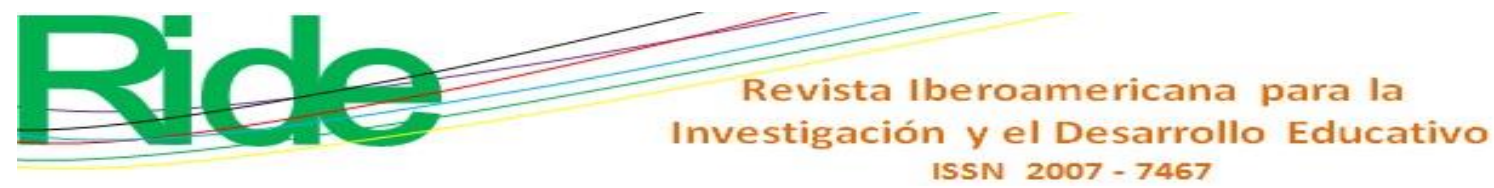

Impression Management. Journal of Work and Organizational Psychology, 34(2), 63-68. Retrieved from https://doi.org/10.5093/jwop2018a8

Díaz, L., Díaz, D., Isla, R., Hernández, E. y Rosales, C. (2012). Adaptación al español de la escala de desempeño cívico de Coleman y Borman (2000) y análisis de la estructura empírica del constructo. Journal of Work and Organizational Psychology, 28(3), 135149. Recuperado de http://dx.doi.org/10.5093/tr2012a11

Diene, M., Diene, B. and Azomahou, T. T. (2016). Human Capital Productivity, Endogenous Growth, and Welfare: The Role of Uncertainty. Macroeconomic Dynamics, 20(8), 2067-2092. Retrieved from https://doi.org/10.1017/S1365100515000309

Di Doménico, A. y De Bona, G. (2005). Activos intangibles en organizaciones de educación superior: medición e indicadores del capital intelectual. En Efrón, M. H. y Pérez, A. (eds.), Aportes al debate sobre la gestión universitaria I (pp. 78-89). Buenos Aires, Argentina: De los cuatro vientos.

Durán, A. (2016). Modelo de gestión del talento humano para la Escuela Superior Politécnica de Chimborazo. Revista Ciencia Unemi, 9(17), 36-43.

Edvinsson, L. y Malone, M. (1999). El capital intelectual. Cómo identificar y calcular el valor de los recursos intangibles de su empresa. Barcelona, España: Gestión 2000.

Elisondo, R. C. (2015). La creatividad como perspectiva educativa. Cinco ideas para pensar los contextos creativos de enseñanza y aprendizaje. Revista Actualidades Investigativas en Educación, 15(3), 1-23. Recuperado de http://dx.doi.org/10.15517/aie.v15i3.20904

Escandón, D., Arias, A. y Salas, J. (2012). Recursos y capacidades que inciden en el desempeño de los subsectores económicos colombianos 2003-2004: un acercamiento desde la teoría basada en recursos. Ingeniería y Competitividad, 14(2), 53-67. Recuperado de https://doi.org/10.25100/iyc.v14i2.2654

Euroforum. (1998). Medición del capital intelectual. Madrid, España: Euroforum.

Felício, J. A., Couto, E. and Caiado, J. (2014). Human capital, social capital and organizational performance. Management Decision, 52(2), 350-364. Retrieved from https://doi.org/10.1108/MD-04-2013-0260

Flores, A. J. Álvarez, M. y Pedraza, N. A. (2020). El capital estructural y su relación estratégica con el desempeño organizacional en el estado de Tamaulipas (México). 

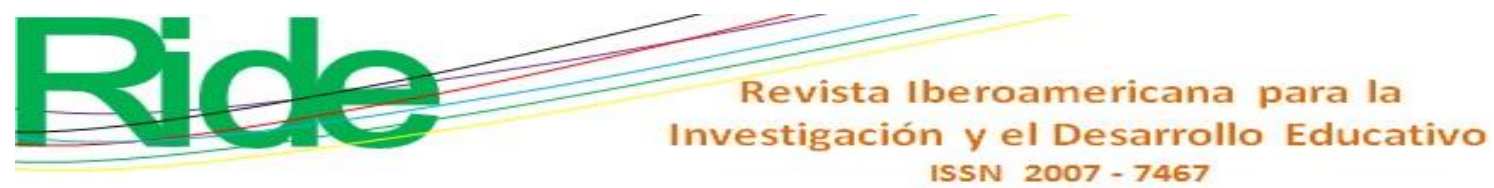

Entramado, 16(1), 44-59. Recuperado de http://dx.doi.org/10.18041/19003803/entramado.1.6078

Fogaca, N., Barbosa, M. C., Campos, M. C., Pereira, L. and Coelho, F. A. (2018). Job Performance Analysis: Scientific Studies in the Main Journals of Management and Psychology from 2006 to 2015. Performance Improvement Quarterly, 30(4), 231247. Retrieved from https://doi.org/10.1002/piq.21248

Gates, S. and Langevin, P. (2013). Human capital measures, strategy and performance: HR managers' perceptions. Accounting Auditing and Accountability Journal, 23(1), 111132. Retrieved from https://doi.org/10.1108/09513571011010628

Gómez, V. (2016). Evidencias del efecto del capital intelectual en el desempeño de empresas de la República Dominicana. Ciencias y Sociedad, 41(4), 823-868. Recuperado de https://doi:10.22206/cys.2016.v41i4.pp823-868

Gorriti, M. (2007). La evaluación del desempeño en administraciones públicas españolas. Revista de Psicología del Trabajo y de las Organizaciones, 23(3), 367-387.

Hamadamin, H. H. and Atan, T. (2019). The Impact of Strategic Human Resource Management Practices on Competitive Advantage Sustainability: The Mediation of Human Capital Development and Employee Commitment. Sustainability, 11(20), 119. Retrieved from https://doi.org/10.3390/su11205782

Hernández, B. R. (2017). Desarrollo de competencias gerenciales en los docentes de la Licenciatura en Administración de Empresas de UNEDL. Revista Iberoamericana para la Investigación y el Desarrollo Educativo, 8(15), 1-26. Recuperado de https://doi.org/10.23913/ride.v8i15.305

Hernández, I., Alvarado, J. C. y Luna, S. M. (2015). Creatividad e innovación: competencias genéricas o transversales en la formación profesional. Revista Virtual Universidad Católica del Norte, 44, 135-151.

Hernández, R., Fernández, C. y Baptista, P. (2014). Metodología de la investigación. México: McGraw Hill.

Herrera, A. L. (2017). Un modelo de perfil para gestión de personal: "Diez competencias del docente de posgrado". Revista Global de Negocios, 5(8) 1-28. 


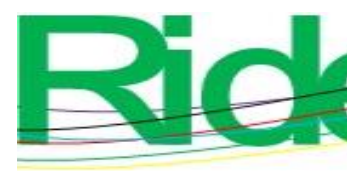

Revista Iberoamericana para la Investigación y el Desarrollo Educativo ISSN $2007-7467$

Huang, Y. C. and Jim, Y. C. (2010). Intellectual capital and knowledge productivity: the Taiwan biotech industry. Management Decision, 48(4), 580-599. Retrieved from https://doi.10.1108/00251741011041364

Ifeanyichukwu, S. (2017). The challenges of human capital development in Nigeria: a theoretical insight. Humanities, Arts and Social Sciences Studies, 17(2), 41-74. Retrieved from https://doi.org/10.14456/sujsha.2017.14

Jiménez, Y. I. (2019). ¿Cómo desarrollar competencias de creatividad e innovación en la educación superior? Caso: carreras de ingeniería del Instituto Politécnico Nacional. Revista Iberoamericana para la Investigación y el Desarrollo Educativo, 9(18), 121. Recuperado de https://doi.org/10.23913/ride.v9i18.427

Kalia, N. and Bhardwaj, B. (2019). Contextual and Task Performance: Do Demographic and Organizational Variables Matter? Rajagiri Management Journal, 13(2), 30-42. Retrieved from https://doi.org/10.1108/RAMJ-09-2019-0017

Keeley, B. (2007). Human capital: How what you know shapes your life. Paris, France: Organisation for Economic Co-operation and Development.

Krichesky, G. J. y Murillo, F. J. (2018). la colaboración docente como factor de aprendizaje y promotor de mejora. Un estudio de casos. Educación XX1, 21(1),135-155. Recuperado de https://doi.org/10.5944/educxx1.20181

Marchezi, A., von Borell, B. F., Matos, A. y dos Santos, A. (2019). Humor at work: A study about the relationship between humor styles, satisfaction with management and individual job performance. Revista de Administración de Brasil de la UFSM, 12(4), 803-820. Retrieved from https://doi.org/10.5902/1983465919382

Mariño, R. M., Rodríguez, J. M. y Rubio, L. (2013). Análisis de los atributos y variables que configuran el capital humano. Una aplicación en el sector bancario andorrano. Ponencia presentada en el XXVII Congreso Anual AEDEM. Huelva, del 5 al 7 de junio de 2013.

Martín, A. y Morales, J. A. (2013). Colaboración educativa en la sociedad del conocimiento. Apertura, 5(1), 1-11.

Martínez, M., Hernández, M. del C. y Gómora, J. Y. (2016). Modelo de competencias directivas en escenarios globales para las instituciones de educación superior. RIDE 

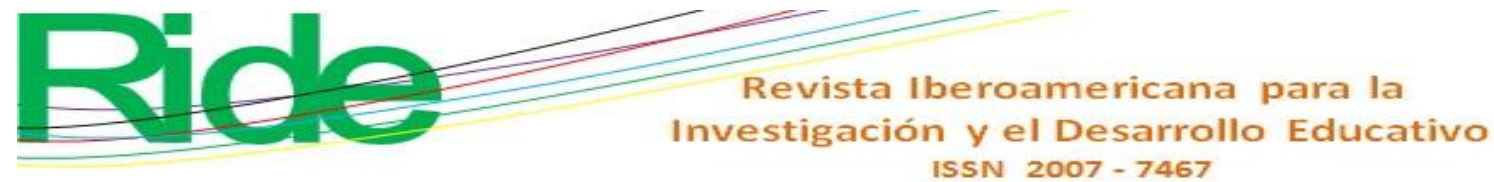

Revista Iberoamericana para la investigación y el Desarrollo Educativo, 6(12), 321333.

McGuirk, H., Lenihan, H. and Hart, M. (2015). Measuring the impact of innovative human capital on small firms' propensity to innovate. Research Policy, 44(4), 965-976. Retrieved from https://doi.org/10.1016/j.respol.2014.11.008

Milkovich, G. y Boudreau, J. (1994). Dirección y administración de recursos humanos. Un enfoque de estrategia. Estados Unidos: Addison-Wesley Iberoamericana.

Montero, L. (2011). El trabajo colaborativo del profesorado como oportunidad formativa. CEE Participación Educativa, 16(1), 69-88.

Morales, L. E., Jacobo, C. A., Ochoa, S. e Ibarra, L. E. (2020). Capital intelectual y desempeño organizacional: el caso de las instituciones de educación básica en México. Pensamiento y Gestión, 47(1), 180-202. Recuperado de http://dx.doi.org/10.14482/pege.47.6342

Moreno, T. (2006). La colaboración y la colegialidad docente en la universidad: del discurso a la realidad. Perfiles Educativos, 28(112), 98-130.

Organisation for Economic Co-operation and Development [OECD]. (2019). Higher Education in Mexico: Labour Market Relevance and Outcomes. Paris, France: OECD Publishing. Retrieved from https://doi.org/10.1787/9789264309432-en

Pardo, C. E. y Díaz, O. L. (2014). Desarrollo del talento humano como factor clave para el desarrollo organizacional, una visión desde los líderes de gestión humana en empresas de Bogotá D.C. Suma de Negocios, 5(11), 39-48. Recuperado de https://doi.org/10.1016/S2215-910X(14)70018-7

Pelinescu, E. (2015). The Impact of Human Capital on Economic Growth. Procedia Economics and Finance, 22, 184-190. Retrieved from https://doi.org/10.1016/S22125671(15)00258-0

Ramos, P. J., Barrada, J. R., Fernández, E. and Koopmans, L. (2019). Assessing Job Performance Using Brief Self-report Scales: The Case of the Individual Work Performance Questionnaire. Journal of Work and Organizational Psychology, 35(3), 195-205. Retrieved from https://doi.org/10.5093/jwop2019a21 


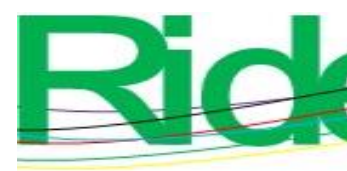

Revista Iberoamericana para la Investigación y el Desarrollo Educativo ISSN $2007-7467$

Ramírez, D. E. (2015). Capital humano: una visión desde la teoría crítica. Cadernos EBAPE.BR, 13(2), 315-331. Recuperado de http://dx.doi.org/10.1590/1679395114754

Rodríguez, J. M. y Rubio, L. (2006). Propuesta de creación de un modelo de capital intelectual hotelero latinoamericano. Estudios Turísticos, 167, 55-90.

Robbins, S. (2004). Comportamiento organizacional. México: Prentice Hall.

Roos, J., Roos, G., Dragonetti, N. C. y Edvinsson, L. (2001). Capital intelectual. El valor intangible de la empresa. Barcelona, España: Paidós.

Ruggeri, G. and Yu, W. (2000). On the Dimensions of Human Capital: An Analytical Framework. Atlantic Canada Economics Association Papers, 29(1), 189-102.

Ruíz, M., Jaraba, B. y Romero, L. (2005). Competencias laborales y la formación universitaria. Psicología desde el Caribe, (16), 64-91.

Sackett, P. R. (2002). The Structure of Counterproductive Work Behaviors: Dimensionality and Relationships with Facets of Job Performance. International Journal of Selection and Assessment, 10(1-2), 5-11. Retrieved from https://onlinelibrary.wiley.com/doi/abs/10.1111/1468-2389.00189.

Samá, D. (2020). La gestión del capital humano y la evaluación del desempeño docente en la educación superior: perspectivas y desarrollo. Anuario Ciencia en la UNAH, 18(1), $1-19$.

Sánchez, A.J., Melián, A. y Hormiga, E. (2007). El concepto de capital intelectual y sus dimensiones. Investigaciones Europeas de Dirección y Economía de la Empresa, 13(2), 97-111.

Segredo, A. M. (2016). Desarrollo organizacional. Una mirada desde el ámbito académico. Educación Médica, $\quad$ 17(1), 3-8. $\quad$ Recuperado de http://dx.doi.org/10.1016/j.edumed.2015.09.002

Shih, K. H., Chang, C. J. and Lin, B. (2010). Assessing knowledge creation and intellectual capital in banking industry. Journal of Intellectual Capital, 11(1), 74-89. Retrieved from https://doi.org/10.1108/14691931011013343

Spector, P. E., Fox, S., Penney, L. M., Bruursema, K., Goh, A. and Kessler, S. (2006). The dimensionality of counterproductivity: Are all counterproductive behaviors created 

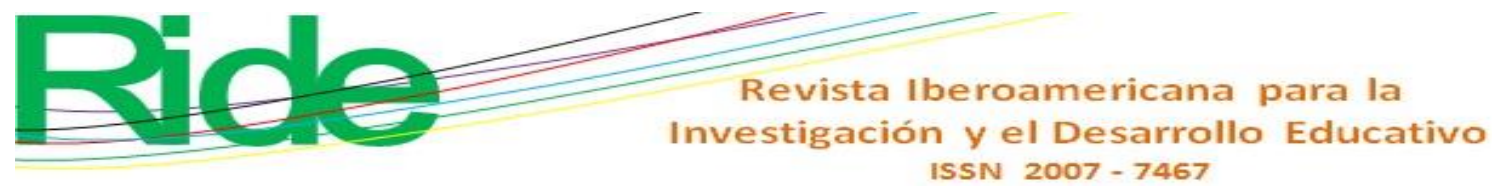

equal? Journal of Vocational Behavior, 68(3), 446-460. Retrieved from https://doi:10.1016/j.jvb.2005.10.005

Tobón, Y. (2015). La nueva era digital en la educación. Ventana Informática, 32(1), 29-45. https://doi.org/10.30554/ventanainform.32.1095.2015

Valdés, S., Ocegueda, J. M. y Romero, A. (2018). La calidad de la educación y su relación con los niveles de crecimiento económico en México. Economía y Desarrollo, 159(1), 61-79.

Vallejo, V. S. y Portalanza, A. (2017). Importancia de la gestión del talento humano como estrategia para la atracción y retención de docentes en las organizaciones educativas de Ecuador. Podium, (edición especial), 145-168.

Vasconcelo, R. (2017). La relación del capital intelectual y el desempeño organizacional en el sector empresarial de Tamaulipas. (Tesis doctoral). Universidad Autónoma de Tamaulipas, México.

Vilcamichi, J. (2017). Clima laboral y desempeño contextual en los docentes de la Institución Educativa Estatal Mariscal Cáceres de Ayacucho, 2017. (Tesis de pregrado). Universidad Alas Peruanas, Perú.

Villegas, E., Hernández, M. y Salazar, B. (2017). La medición del capital intelectual y su impacto en el rendimiento financiero en empresas del sector industrial en México. Contaduría y Administración, 62, 184-206. Recuperado de https://doi.org/10.1016/j.cya.2016.10.002

Woodman, R. W., Sawyer, J. E. and Griffin, R. W. (1993). Toward a Theory of Organizational Creativity. Academy of Management Review, 18(2), 293-321. Retrieved from https://doi.org/10.2307/258761 